\title{
Controllable Growth of the ZnO Nanorod Arrays on the Al Substrate and Their Reversible Wettability Transition
}

\author{
Hong Li, ${ }^{1}$ Hongyan Liu, ${ }^{2}$ Yushan $\mathrm{Li}^{2}{ }^{2}$ and Qinzhuang Liu ${ }^{1}$ \\ ${ }^{1}$ School of Physics and Electronic Information, Huaibei Normal University, Huaibei 235000, China \\ ${ }^{2}$ Department of Physics, Heze University, Heze 274015, China \\ Correspondence should be addressed to Qinzhuang Liu; qzliu@mail.ustc.edu.cn
}

Received 8 December 2016; Accepted 17 January 2017; Published 23 February 2017

Academic Editor: Paresh Chandra Ray

Copyright (c) 2017 Hong Li et al. This is an open access article distributed under the Creative Commons Attribution License, which permits unrestricted use, distribution, and reproduction in any medium, provided the original work is properly cited.

High-quality $\mathrm{ZnO}$ nanorod arrays are formed using the $\mathrm{ZnO}$ nanoflakes on the $\mathrm{Al}$ substrate as seed layer. A reversible wettability transition can be easily achieved via alternation of UV irradiation and dark storage. The physical adsorption of the water molecules on the surface of $\mathrm{ZnO}$ nanorod arrays is considered to be responsible for this transition, which is confirmed by $\mathrm{X}$-ray photoelectron spectroscopy.

\section{Introduction}

Wettability design and manipulation have received particular attention in modern society because of its potential applications [1-3]. Wettability results from low surface free energy and surface morphology with special micro- and nanorough structures $[4,5]$. Recently, with the rapid development of the smart devices, such as intelligent small droplet manipulation, reversible wettability switch has become a research focus and been realized by modification of responsive materials [6]. Such responsive materials present intrinsic reaction when they face the different environmental stimuli such as light illumination [7], $\mathrm{pH}$ [8], electric field [9], and temperature [10]. Being a photoresponsive semiconductor, the $\mathrm{ZnO}$ has aroused great attention because of its special electronic, optical, and acoustic properties [11]. Reversible wettability switch on the solid surface modified by $\mathrm{ZnO}$ nanostructure has been reported [12]. Reversible superhydrophobicity to superhydrophilicity switch was observed on the glass wafer coated by $\mathrm{ZnO}$ nanorods [13].

In this paper, high-quality $\mathrm{ZnO}$ nanorod arrays are achieved by hydrothermal and chemical vapor deposition route on the $\mathrm{Al}$ substrate. The wettability transition between the superhydrophobicity and superhydrophilicity is observed via alternation of UV irradiation and dark storage. The nanostructure and special photoelectric properties of the $\mathrm{ZnO}$ are two important factors for the wettability transition.

\section{Methods}

The procedure to growing high-quality vertical $\mathrm{ZnO}$ nanorod arrays consists of two steps: (1) growing two-dimensional $\mathrm{ZnO}$ nanoflakes on the $\mathrm{Al}$ substrates using low-temperature hydrothermal route and (2) the formation of high-quality vertical $\mathrm{ZnO}$ nanorod arrays on the surface of two-dimensional $\mathrm{ZnO}$ nanoflakes through chemical vapor deposition route.

In the first step, $\mathrm{Al}$ substrate was cleaned thoroughly in acetone for about $30 \mathrm{~min}$ by ultrasonic waves and cleaned with deionized water in sequence. The Al substrate was suspended in the beaker filled with aqueous solution of zinc nitrate hydrate $(8 \mathrm{mM})$ and hexamethylenetetramine $(8 \mathrm{mM})$ at $95^{\circ} \mathrm{C}$ for $2 \mathrm{~h}$. The $\mathrm{Al}$ substrate was then taken out from the solution, rinsed with deionized water, and dried by a nitrogen stream. Last, the sample was annealed at $450^{\circ} \mathrm{C}$ in air for $30 \mathrm{~min}$.

In the second step, the alumina boat with $\mathrm{Zn}$ powder (purity: 99.999\%) was placed into the horizontal tube furnace. The sample which was prepared in the first step was put horizontally on the downstream side of the alumina boat at a distance of $8 \mathrm{~cm}$. Before the growth, argon was introduced 


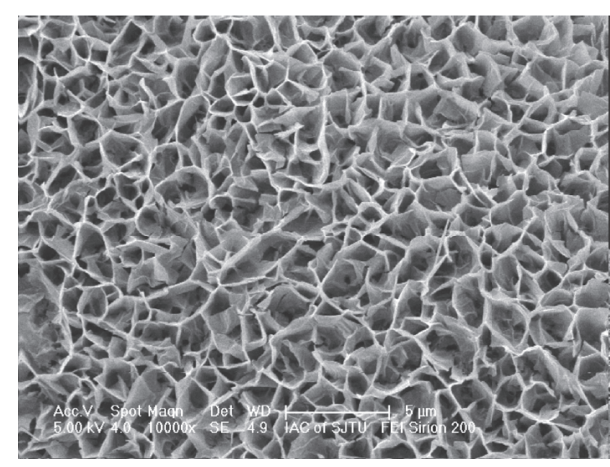

(a)

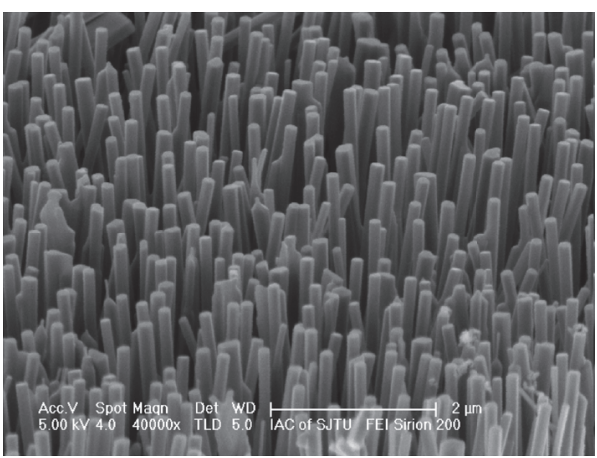

(c)

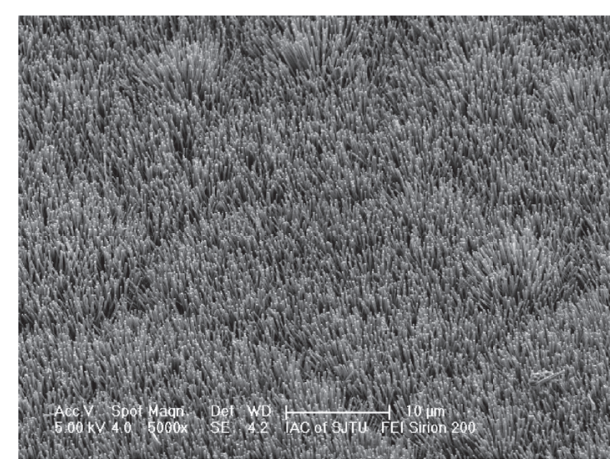

(b)

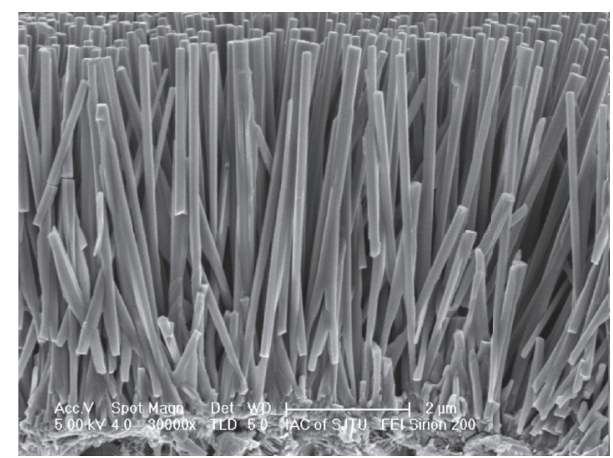

(d)

FIGURE 1: SEM images of the as-grown $\mathrm{ZnO}$ samples on the $\mathrm{Al}$ substrate. (a) Large-area view of the $\mathrm{ZnO}$ nanoflakes on the $\mathrm{Al}$ substrate, (b) top images of the $\mathrm{ZnO}$ nanorod arrays and (c) high magnification $\mathrm{ZnO}$ nanorod arrays, and (d) side views of the $\mathrm{ZnO}$ nanorod arrays.

into the system through a mass-flow controller with a flow $120 \mathrm{sccm}$ and the pressure was maintained at $80 \mathrm{~Pa}$. The temperature of the furnace was changed linearly with time to $600^{\circ} \mathrm{C}$ at the rate of $20^{\circ} \mathrm{C} / \mathrm{min}$. Subsequently, oxygen was given to the system at a flow rate of $100 \mathrm{sccm}$. The reaction was carried out at about $600^{\circ} \mathrm{C}$ for $40 \mathrm{~min}$. After that, the furnace was cooled to room temperature, while argon and oxygen flow was stopped. The as-grown film was stored in the dark environment for a week before being measured.

The morphologies of sample nanostructure were characterized by scanning electron microscopy (SEM, Philips Sirion 200). The component of the sample was characterized by $\mathrm{X}$ ray diffraction (XRD, D/max-2200/PC). The water contact angles (WCAs) on the surface were measured with deionized water of $5 \mu \mathrm{l}$ by using an optical contact angle meter system at ambient temperature (Data Physics Instrument GmbH, Germany). The X-ray photoelectron spectroscopy spectrum (XPS) of the samples was measured by Thermo ESCALAB 250 .

\section{Results and Discussions}

Figure 1(a) shows the typical morphology of $\mathrm{ZnO}$ nanoflakes on the Al substrate using low-temperature hydrothermal route. Many sheet-like $\mathrm{ZnO}$ nanoflakes were produced and nearly vertical to the Al substrate. Figure $1(\mathrm{~b})$ is image of the $\mathrm{ZnO}$ nanorod arrays coated on the $\mathrm{ZnO}$ nanoflakes.
Figure 1(c) is the further magnified image. From the SEM image as showed in Figure 1(c), the $\mathrm{ZnO}$ nanorod arrays have a flat surface morphology, with almost the same diameters of about $150 \mathrm{~nm}$. Side image of the SEM view of the arrays (Figure $1(\mathrm{~d})$ ) suggests that the $\mathrm{ZnO}$ nanorod arrays grow completely vertically and the height is about $5 \mu \mathrm{m}$. Figure 2 compared the XRD spectrum of the $\mathrm{ZnO}$ nanorod arrays (Figure 2(a)) with the $\mathrm{ZnO}$ nanoflakes (Figure 2(b)) on the $\mathrm{Al}$ substrate. The XRD spectrum of the $\mathrm{ZnO}$ nanorod arrays is almost the same as the $\mathrm{ZnO}$ nanoflakes, indicating that the orientation of the $\mathrm{ZnO}$ nanoflakes is of great importance to the orientation of the $\mathrm{ZnO}$ nanorod arrays. It is well-known that the effect of seeds layer is very important in fabricating high-quality vertical $\mathrm{ZnO}$ nanorod arrays. So we can deduce that the role of $\mathrm{ZnO}$ nanoflakes on the $\mathrm{Al}$ substrate is seeding which directly leads to the formation of $\mathrm{ZnO}$ nanorod arrays.

The wettability of the $\mathrm{ZnO}$ nanorod arrays is studied by water contact angle (WCA) measurement. The WCA on the surface coated by $\mathrm{ZnO}$ nanorod arrays is about $158^{\circ}$ as shown in Figure 3(a). After UV illumination, the WCA is about $0^{\circ}$. After depositing the film which was irradiated by the UV in the dark environment for five days, the film is still superhydrophobic again. This process can be repeated many times and the corresponding process is shown in Figure 4.

Surface free energy and surface morphology have important effects on the surface wettability. The high-quality $\mathrm{ZnO}$ nanorod arrays on the Al substrate in Figure 1 increase the air 


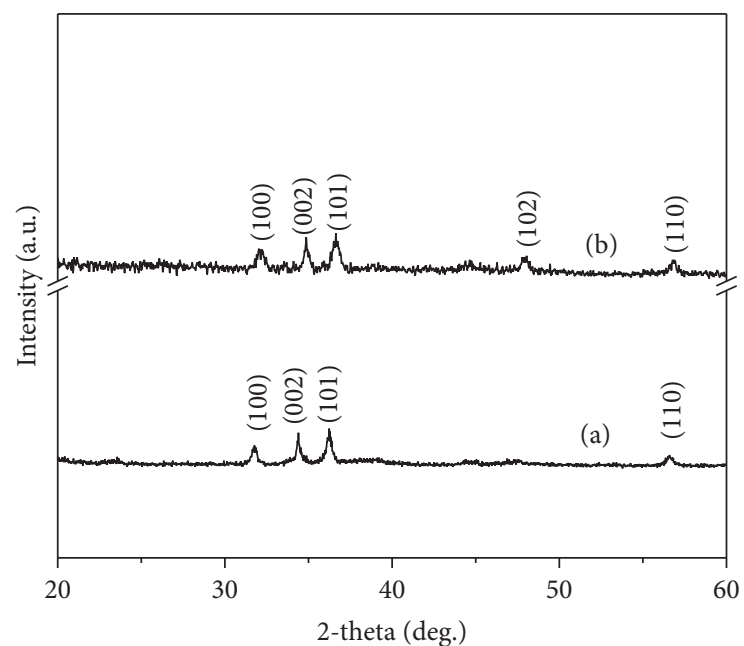

Figure 2: XRD patterns of the as-grown $\mathrm{ZnO}$ samples. (a) $\mathrm{ZnO}$ nanorod arrays. (b) $\mathrm{ZnO}$ nanoflakes.

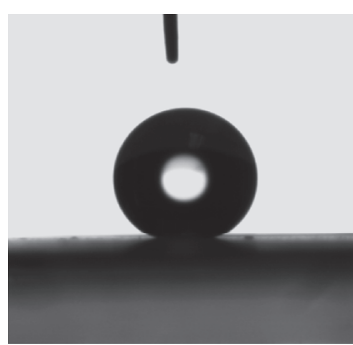

(a)

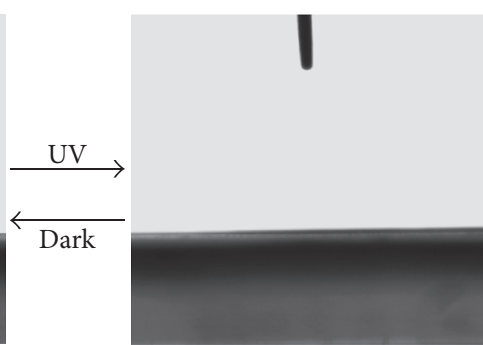

(b)
FIGURE 3: The shape of water droplet on the $\mathrm{ZnO}$ nanorod arrays (a) before UV irradiation and (b) after UV irradiation.

fraction of the water-air interface. This means that the special nanostructure will increase the WCA. The superhydrophobicity of the $\mathrm{ZnO}$ nanorod arrays can be explained by Cassie equation [14]:

$$
\cos \theta^{*}=-1+f_{1}(1+\cos \theta)
$$

where $\theta^{*}$ and $\theta$ are CA on the rough and flat surface and $f_{1}$ is the solid fraction in contact with water. Because the surface roughness of $\mathrm{ZnO}$ nanorod arrays is much higher than $\mathrm{ZnO}$ nanoflakes, much air is easy blocked among the $\mathrm{ZnO}$ nanorod arrays when the water droplet is placed on it, so the value of $f_{1}$ decreases rapidly and the CA increases. This is the reason that the $\mathrm{Al}$ substrate coated by $\mathrm{ZnO}$ nanorod arrays shows superhydrophobicity.

The wettability of the solid is determined by surface free energy and the geometric structure. The geometric structures of the $\mathrm{ZnO}$ nanorod arrays do not change before and after UV irradiation, indicating that the wettability transition is caused by surface free energy. Hole of electron-hole pairs generated in the $\mathrm{ZnO}$ by $\mathrm{UV}$ irradiation will react with lattice oxygen to form surface oxygen vacancies $[15,16]$. Subsequently, water molecules absorbed at the surface oxygen vacancies will produce the hydroxyl groups which lead to the physical adsorption of the water molecules. The hydrophilicity of film

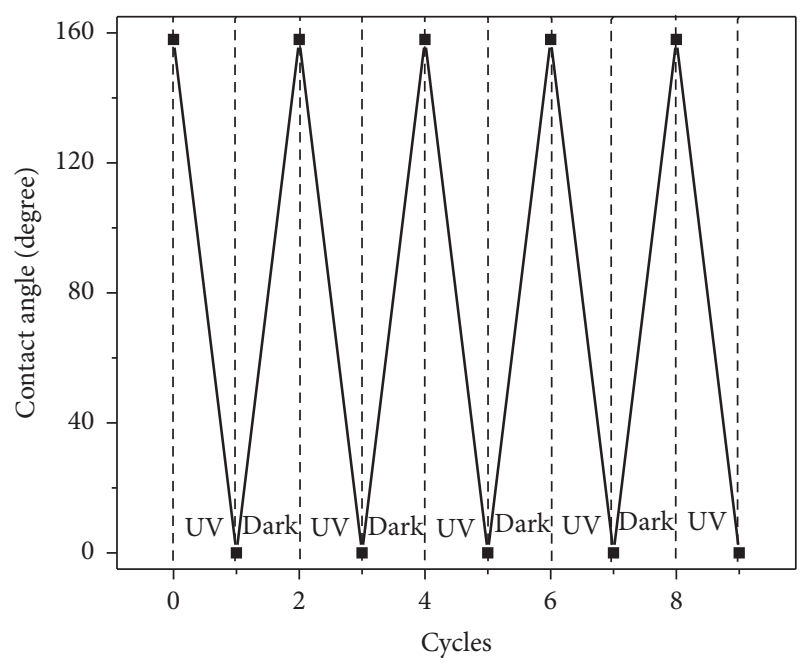

FIGURE 4: Reversible wettability switching by alternating UV irradiation and dark storage.

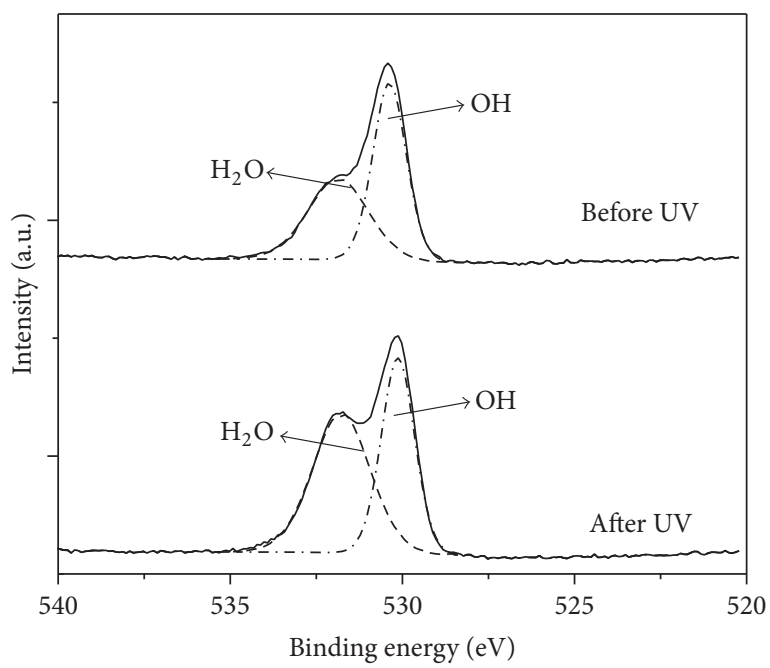

FIGURE 5: X-ray photoelectron spectroscopy spectra of the O 1s level before and after UV irradiation.

increases. Figure 5 shows the XPS of $\mathrm{ZnO}$ nanorod arrays before and after UV irradiation. The shoulder and intensity of the $\mathrm{O}$ 1s at the higher binding energy are increased. This confirms the existence of physical adsorption of the water molecules on the surface of $\mathrm{ZnO}$ nanorod arrays. From Wenzel equation [17],

$$
\cos \theta^{*}=r \cos \theta
$$

where $r$ is rough factor and the hydrophilicity of film will be enhanced to superhydrophilicity because of the special nanostructure. Oxygen atoms gradually take the place of the hydroxyl groups adsorbed on the $\mathrm{ZnO}$ nanorod arrays when the film was placed in the dark. In the end, the surface wettability changes back to the superhydrophobicity.

In order to acquire the detailed information about the effect of UV illumination on the WCA, Figure 6 has given the WCA as the function of UV illumination time. It can be seen 


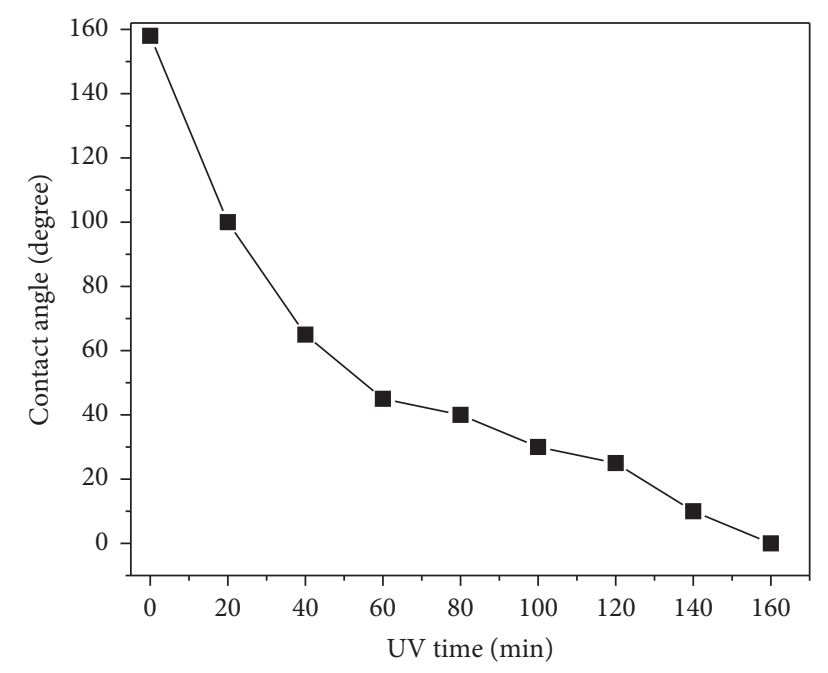

FIGURE 6: Contact angle versus UV irradiation time for the water droplet on the surface of $\mathrm{ZnO}$ nanorod arrays.

that the WCA decreases abruptly from $158^{\circ}$ to $50^{\circ}$ about after 60 min of UV irradiation because of the high speed yielding of electron-hole pairs after UV irradiation. With the increase of illumination time from 60 to $160 \mathrm{~min}$, the change speed of WCA is slow and, at last, the wettability of film changes from superhydrophobicity to superhydrophilicity.

\section{Conclusions}

Dense and vertically aligned $\mathrm{ZnO}$ nanorod arrays with a large area are fabricated by a simple two-step process on the $\mathrm{Al}$ substrate. The as-grown film shows good superhydrophobicity and the contact angle is about $158^{\circ}$. The film shows good superhydrophilicity and the contact angle is about $0^{\circ}$ after UV irradiation. Reversible wettability transition is achieved via alternation of UV irradiation and dark storage. The nanostructure and special photoelectric properties of the $\mathrm{ZnO}$ are two important factors for this behavior.

\section{Competing Interests}

The authors declare that there is no conflict of interests regarding the publication of this paper.

\section{Acknowledgments}

This work was supported by Natural Science Foundation of Anhui Province (no. 1408085QA19) and Natural Science General Foundation of Anhui Higher Education Institutions of China (no. KJ2014B03).

\section{References}

[1] L. Feng, Z. Zhang, Z. Mai et al., "A super-hydrophobic and super-oleophilic coating mesh film for the separation of oil and water," Angewandte Chemie - International Edition, vol. 43, no. 15, pp. 2012-2014, 2004.
[2] T. Sun, L. Feng, X. Gao, and L. Jiang, "Bioinspired surfaces with special wettability," Accounts of Chemical Research, vol. 38, no. 8, pp. 644-652, 2005.

[3] X. Feng and L. Jiang, "Design and creation of superwetting/antiwetting surfaces," Advanced Materials, vol. 18, no. 23, pp. 3063-3078, 2006.

[4] B. K. Nayak, P. O. Caffrey, C. R. Speck, and M. C. Gupta, "Superhydrophobic surfaces by replication of micro/nanostructures fabricated by ultrafast-laser-microtexturing," Applied Surface Science, vol. 266, pp. 27-32, 2013.

[5] Y. Coffinier, S. Janel, A. Addad et al., "Preparation of superhydrophobic silicon oxide nanowire surfaces," Langmuir, vol. 23, no. 4, pp. 1608-1611, 2007.

[6] W. Li, T. Guo, T. Meng et al., "Enhanced reversible wettability conversion of micro-nano hierarchical $\mathrm{TiO}_{2} / \mathrm{SiO}_{2}$ composite films under UV irradiation," Applied Surface Science, vol. 283, pp. 12-18, 2013.

[7] H. Liu, L. Feng, J. Zhai, L. Jiang, and D. Zhu, "Reversible wettability of a chemical vapor deposition prepared $\mathrm{ZnO}$ film between superhydrophobicity and superhydrophilicity," Langmuir, vol. 20, no. 14, pp. 5659-5661, 2004.

[8] X. Yu, Z. Wang, Y. Jiang, F. Shi, and X. Zhang, "Reversible $\mathrm{pH}$-responsive surface: from superhydrophobicity to superhydrophilicity," Advanced Materials, vol. 17, no. 10, pp. 1289-1293, 2005.

[9] B. Kakade, R. Mehta, A. Durge, S. Kulkarni, and V. Pillai, "Electric field induced, superhydrophobic to superhydrophilic switching in multiwalled carbon nanotube papers," Nano Letters, vol. 8, no. 9, pp. 2693-2696, 2008.

[10] B. Xue, L. Gao, Y. Hou, Z. Liu, and L. Jiang, “Temperature controlled water/oil wettability of a surface fabricated by a block copolymer: application as a dual water/oil on-off switch," Advanced Materials, vol. 25, no. 2, pp. 273-277, 2013.

[11] J. Lü, K. Huang, X. Chen et al., "Reversible wettability of nanostructured $\mathrm{ZnO}$ thin films by sol-gel method," Applied Surface Science, vol. 256, no. 14, pp. 4720-4723, 2010.

[12] H. Li, M. J. Zheng, S. D. Liu, L. Ma, C. Q. Zhu, and Z. Z. Xiong, "Reversible surface wettability transition between superhydrophobicity and superhydrophilicity on hierarchical micro/nanostructure $\mathrm{ZnO}$ mesh films," Surface and Coatings Technology, vol. 224, pp. 88-92, 2013.

[13] X. Feng, L. Feng, M. Jin, J. Zhai, L. Jiang, and D. Zhu, "Reversible super-hydrophobicity to super-hydrophilicity transition of aligned $\mathrm{ZnO}$ nanorod films," Journal of the American Chemical Society, vol. 126, no. 1, pp. 62-63, 2004.

[14] A. B. D. Cassie and S. Baxter, "Wettability of porous surfaces," Transactions of the Faraday Society, vol. 40, pp. 546-551, 1944.

[15] W. H. Hirschwald, "Zinc oxide: an outstanding example of a binary compound semiconductor," Accounts of Chemical Research, vol. 18, no. 8, pp. 228-234, 1985.

[16] M. Miyauchi, A. Nakajima, A. Fujishima, K. Hashimoto, and T. Watanabe, "Photoinduced surface reaction on $\mathrm{TiO}_{2}$ and $\mathrm{SrTiO}_{3}$ films: photocatalytic oxidation and photoinduced hydrophilicity," Chemistry of Materials, vol. 12, no. 1, pp. 3-5, 2000.

[17] R. N. Wenzel, "Resistance of solid surfaces to wetting by water," Industrial \& Engineering Chemistry, vol. 28, no. 8, pp. 988-994, 1936. 

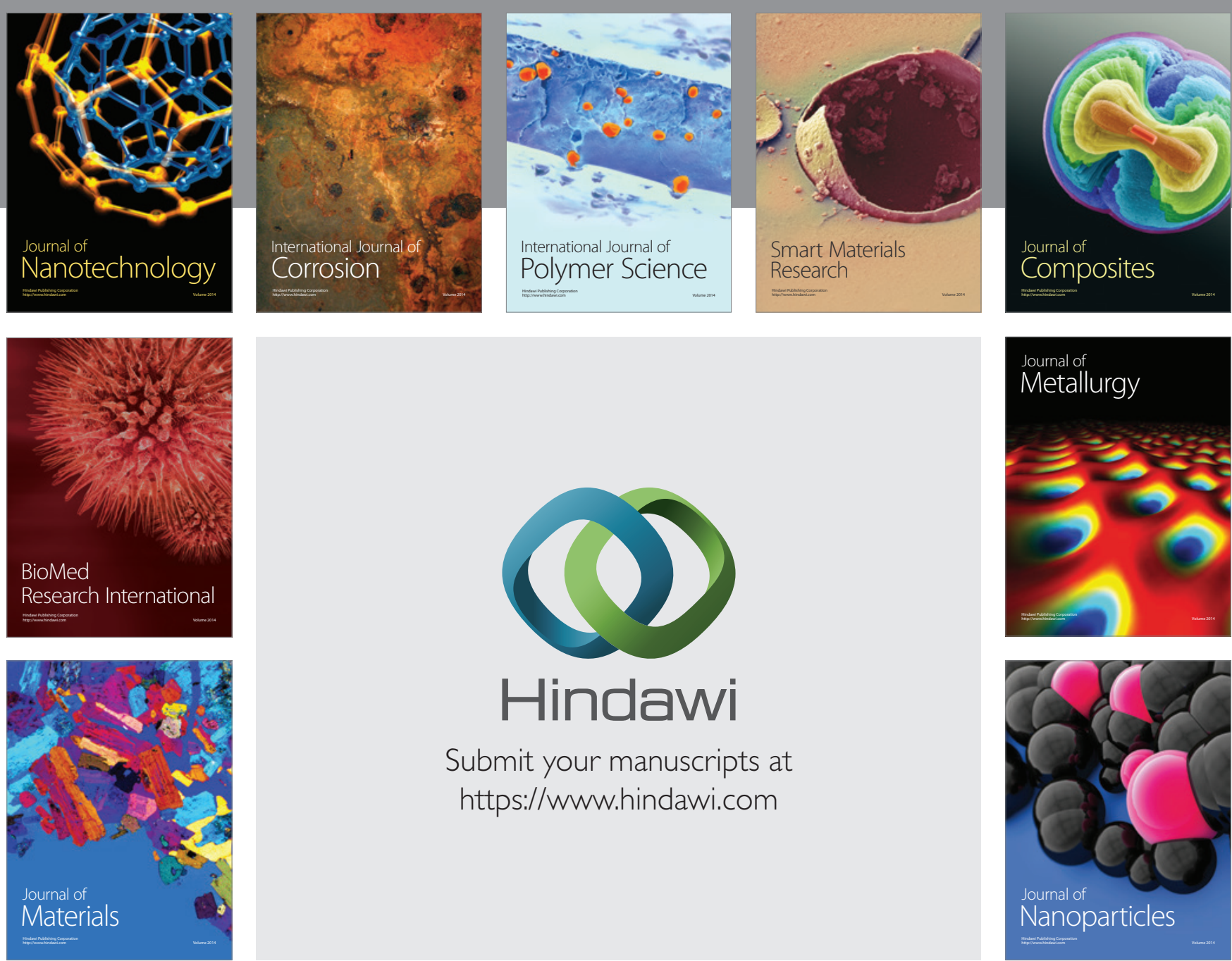

\section{Hindawi}

Submit your manuscripts at

https://www.hindawi.com

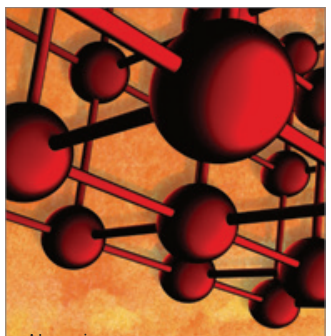

Materials Science and Engineering
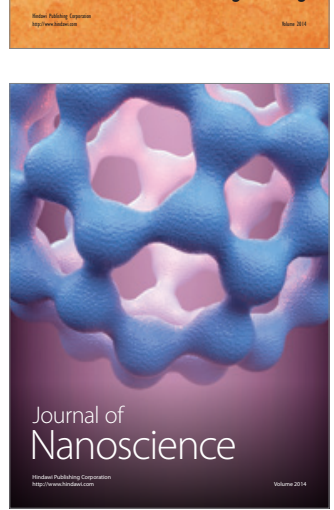
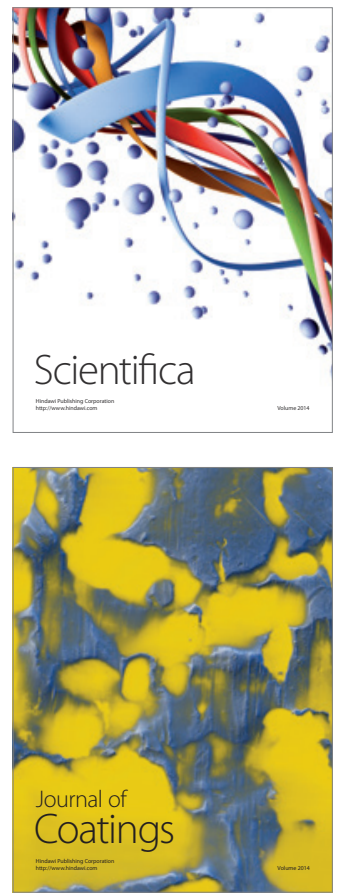
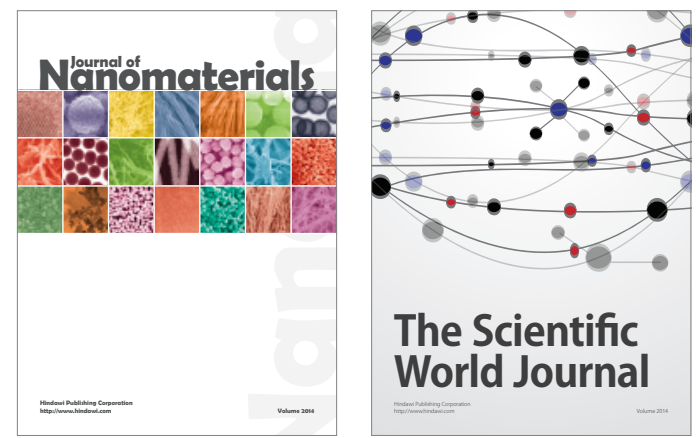

The Scientific World Journal
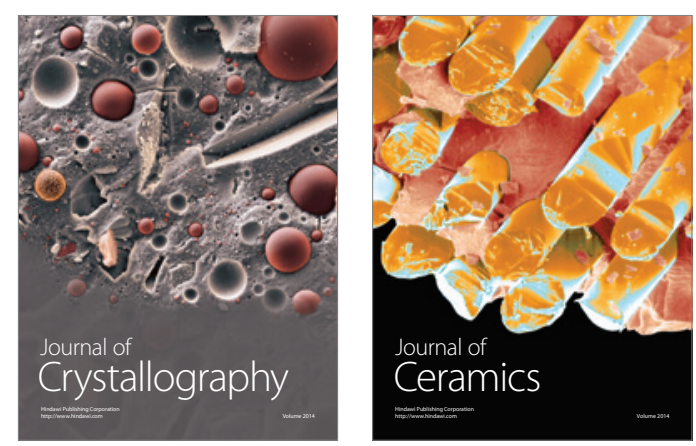
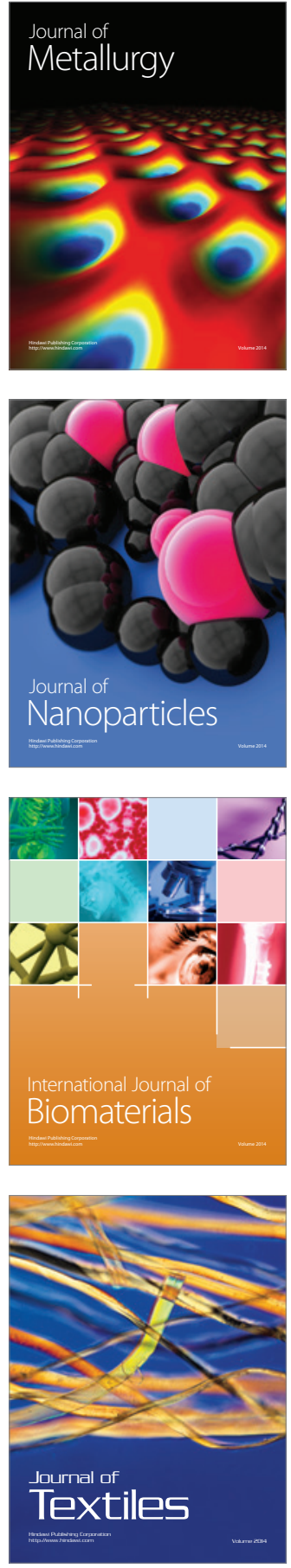